\title{
Where to go in the near future: diverging perspectives on online public service delivery
}

\author{
Alexander van Deursen \\ University of Twente, research program Governments and ICT \\ Department of Media, Communication and Organization \\ P.O. Box 217, 7500 AE Enschede, The Netherlands \\ a.j.a.m.vandeursen@utwente.nl
}

\begin{abstract}
Although the electronic government is under heavy development, a clear vision doesn't seem to exist. In this study 20 interviews among leaders in the field of e-government in the Netherlands resulted in different perspectives on the future of electronic public service delivery. The interviews revealed different objectives and interpretations of the presuppositions regarding citizens' desires. Opinions about channel approaches and 'trigger services' appeared to vary. Furthermore, the respondents didn't agree on the number of contact moments between citizen and government, had different opinions about digital skills, pled for various designs of the electronic government and placed the responsibility for electronic service delivery in different hands. Conclusion is that there is a lack of concepts on how to do things. Everybody talks about eGovernment, but all have different interpretations.
\end{abstract}

Keywords: eServices, perspectives, strategy, policy.

\section{Introduction}

In the 1980's, the term New Public Management (NPM) was invented [1]. The focus of this management vision was on the relationship between governments and their citizens. The accent of the way governments influence their citizens shifted from reinforcement of the law towards service provision. A more service oriented approach would improve the relationship between citizens and governments. The impact of NPM was big. In the second half of the 1990's, most Western countries followed a strategy to improve their public services based on the ideas of NPM [2].

With the rise of the internet in the nineties, an important shift took place in the way the NPM vision was to be accomplished. For governments, it seemed that the ambition to become more citizen centered through the deployment of various different applications of ICT, finally became reality [2]. In the US, the National Performance Review encouraged governments to employ internet in order to improve service levels, cut red tape and make access to governments easier. In 2000, the Lisbon conference covered these topics and it was agreed upon that by 2010 Europe should be the most dynamic knowledge economy in the world [3]. 
Although ICT is seen as the means to accomplish the objectives founded in the NPM vision, research indicates that it isn't the Holy Grail in service delivery. The use of electronic services lags behind with the demand [4]. Lacunas in existing knowledge are identified and it is demonstrated that the internet is still not a general accessible channel due to the lack of the citizens' motivation, a lack of digital skills and a lack of possession of computers and internet access [4]. Also, the use of more traditional service channels, like the telephone and service desks, doesn't decline [5]. Despite these indications, the ICT-policy of the government is characterized by few barely funded presuppositions over what citizens want, how they use ICT and what the consequences are [6]. Due to these presuppositions, developments have led to an increased distribution of the internet, especially at the demand site. For further developments it is important to take sensible steps and make wise decisions on all governmental levels. This requires committed executive leadership [7]. However, although the electronic government is under heavy development, a clear vision of eGovernment doesn't seem to exist: it is too often considered a public variant of eCommerce [8]. In this explorative study different perspectives on future electronic public service delivery are identified by conducting 20 open interviews among leading figures in the field of e-government in the Netherlands. The next section covers the research background and the used methodology. Section 3 summarizes the interviews and in section 4 the conclusions are drawn.

\section{Research background}

While enabling government services to be delivered online is a key target within most of the EU countries' strategies, there is no documentation of an eGovernment framework to guide the process. Guidelines for implementation are also missing from the literature [9]. The models that do exist are often wider than the context of eServices. They sometimes complete, but also exclude each other aspects. Investigating the relevant models and literature globally yields eight themes relevant for future perspectives on eServices. They serve as main topics of conversation in the interviews (interview questions are added at the end of every topic in italic):

1. Objectives [10,11]: Policy advisors can have internal objectives (e.g. efficiency), demand sided objectives (e.g. quality of service delivery) or innovation oriented objectives for offering services online. (What is the most important objective of electronic public serviced delivery?)

2. Presuppositions [6]: The ICT policy of the government is characterized by few barely founded presuppositions about what citizens want. Three dominant assumptions are: citizens wish to distribute information to the government onceonly, citizens would like one single online access point for all governmental organizations and citizens appreciate proactive service delivery [4]. (Are the presuppositions true?)

3. Channels [12]: Four channels can be distinguished for service delivery: Personal (e.g. counter), electronic (e.g. the internet or e-mail), written (e.g. letters and faxes), and the telephone. It becomes more and more obvious that the 
internet is not the perfect one in public service delivery [5]. Multichanneling is defined as the use of multiple service channels within one public service delivery process or the use of different channels for different service delivery processes [12]. However, there are only little concrete interpretations of multichanneling. (What channels will remain in the future and how are they positioned in relation to each other?)

4. Services [6]: A possible explanation for the lagging of the actual use of electronic services is that governments anticipate too little on the popularity of some services [4]. More attention to the development of so called 'trigger services' could cause the amount of use to raise. Although there are some examples of successful electronic services, like electronic tax filing, used by almost $60 \%$ of the Dutch population [13], we still have little knowledge about what characterizes trigger services. (What services might trigger citizens to make more use of electronic public service delivery?)

5. Contact moments [6]: The presuppositions suggest that the number of contacts between citizens and government will change. Proactive service delivery could lead to one-sided contacts, once-only data distribution to a decrease of contacts and deploying one counter for all governmental institutions to a decline of personal contacts. (How will the number of contact moments between government and citizen change in the future?)

6. Digital skills $[6,14,15,16]$ : The Dutch government aims to be in the European top 10 regarding ICT and innovation in 2010 [3]. One of the objectives is to empower the innovation strength of the public sector. At the same time the discussion to what extent the digital divide will manifest itself as a structural problem is going on. A dilemma rises whether public service delivery should aim at improving innovation strength, or at closing the digital divide. (Should governments aim at the skilled or at the laggards? How?)

7. Architecture $[10,11,17]$ : Currently, most institutions have their own front and back office. Current developments seem to lead to integrated back offices. Integrating back offices properly is a complex operation because ICT-facilities within the government are very diverse, as well as on technological maturity, complexity, as on scale. This makes developing common standards difficult. However, online personal portals suppose immediate actualization and therefore a direct connection with the back office. (What will the architecture of electronic service delivery look like in the future?)

8. Responsibility [15]: For realizing electronic service delivery according to the different perspectives respondents forecasted, necessary shifts in responsibility are very likely. (Who should take responsibility for realizing the sketched future vision?)

A number of 20 single interviews are conducted. Interviews are a good way to elicit unanticipated information and to enable great depth and meaning of communication experiences to be explored and recorded [18]. Exploratory single interviews are best suited to generate issues and enable the interviewer to specifically ask about individual opinions and the reasons to make specific choices. For every theme described above, a question was formulated. The main objective was to let the 
respondent talk freely, allowing him or her to generate issues. The semi structured interviews lasted approximately 90 minutes and were held in the respondents' offices.

Twenty policy advisors, eLeaders and scientists on different levels (municipal, provincial, national and executive policy agencies) were selected based on their position and responsibility for eService policy. Furthermore, five scientists known in the eGovernment field with relevant publications were selected. Of the 25 approached respondents 20 agreed upon an interview; four on every governmental level and four scientists.

The data collected during the interviews were analyzed in two steps. First, the interviews were transcribed fully. Second, for every theme a list of factors was extracted using inductive analysis by categorizing the different answers per theme; the different factors emerged out of the data rather than being imposed on them prior to data collection and analysis. The following section outlines the most important findings of the qualitative study. Each of the themes and corresponding factors are discussed in detail. The findings are illustrated with quotations from the respondents. The italic numbers in between parentheses correspond with the number of respondents that elected the corresponding emerged factor.

\section{Interview results}

\subsection{Objectives}

Six objectives for offering public services online can be identified: transparency (3), efficiency (11), innovation (2), quality of service delivery (12) and cutting red tape (1). Efficiency and the quality of service delivery are the most important motives. The former especially at federal executive agencies: "Efficiency, efficiency and efficiency. Everybody profits when we stop squandering money." According to one scientist efficiency is indeed important, because "too many things are performed twice", but the starting point for executing ICT projects should be the perception of citizens. "Current objectives are too much technically oriented. It's all about putting things on the net. The real purpose should flow from society." Federal executive agencies consider quality of service delivery not as an objective, but as a means to improve the efficiency, in contrast with municipalities. A critical remark regarding quality is that although it is an important objective, there will never be a perfect service delivery: "With the continuing of developments it is an unfeasible battle. The electronic government should be realized as efficiently as possible, but at the same time the complexity of the relations in society will increase, which means that the perception of having a better service delivery will never change."

On the national level the opinions about the importance of a strong innovation position vary. Stated disparagement is that the government doesn't pay the bill directly for not being innovative, contrary to private organizations doing eCommerce. Because of this, two respondents don't expect major changes in the future.

Transparency and image are mentioned as well. One respondent believes that transparency will track and eliminate the laxness of civil servants. Image is important 
with respect to comparisons with the private sector, which indicates that the government should make more use of the current developments.

Finally, one scientist considers electronic service delivery as an objective itself for pushing the electronic government as a whole. The attention for service delivery is disproportionate according to this respondent. "It is an important theme, but at the same time the electronic government is so much more than service delivery alone. The time has come that our attention shifts to other aspects, like eDemocracy.”

\subsection{Presuppositions}

Categorizing the different opinions regarding presuppositions is difficult because they vary a lot. However, most of the respondents on all levels seem to go along with all three presuppositions.

\section{Once-only data distribution}

Once-only data distribution to the government has sweeping consequences for the way public organizations work. It requires coherence and unity in information systems. The interviews show that almost everybody agrees that it will pay off soon. Only two respondents hesitate. One thinks it is a fabrication of politicians and the other can imagine very well that citizens don't want governments to share their personal data. The general point of view is well phrased in the following quotation: "Why register the same data at different places? Let the governments communicate with each other. The government should make more use of its administrative possibilities. This makes it much easier for citizens."

Although most respondents have the same opinion, they doubt the feasibility of the whole operation. "It is very expensive to realize all these exchanges between back offices and we are already working on it for a long time. The problem is that organizations don't trust each other just like that”. In the future most respondents believe that integrating back offices will go more effortless.

Another cited aspect is privacy. Some respondents think this will be a huge problem in the future against what governments should put great effort. Governments will have to make very clear who has access to what data. Other respondents believe that everybody will understand that data are going to be exchanged and that distrust will wear out, "especially when citizens profit”.

\section{One online access point for all governments}

Opinions regarding one online access point for all governments are diverse. "There is a healthy distrust against the government. Personal all-embracing portals are good initiatives, but it is necessary to perform research among citizens first. I won't be surprised when nobody is going to use them. Governments cannot permit themselves anymore to create solutions that nobody uses."

Some respondents are convinced that one online access point is going to be a success. They also believe that organizations are going to lose their own identity: "A citizen or company doesn't care whether you are a municipality or a federal executive agency; they just want their service or product. This is a matter of clever bonding.” 
Other respondents consider this view as a utopia, taken the current number of access points into account. "For service delivery, citizens want to go to the website they are used to. For taxes, they would like to see the tax administration's logo. Organizations are going to keep their own look and feel. It is not very sensible to put everything behind one portal."

Two other mentioned perspectives are 'one single point of contact' (citizens are redirected to the right institution) and 'no-wrong-door' (citizens can do everything at every institution, which results in competition on product level).

\section{Proactive service delivery}

Most respondents believe it is inevitable that proactive service delivery becomes reality. They vision a government that takes all initiatives itself and becomes more helpful. "When I make pancakes and bring the batter with me, but forget the milk, they will tell me.” It is believed that citizens will be better served when organizations tune their data and that this will become ordinary soon.

One scientist is convinced that public organizations are going to cooperate in the near future, but doubts whether it is desirable. "We also need active citizens; there is a chance that we make them lazy using proactive service delivery. In the near future everything will be spoon fed. Citizens won't lose themselves anymore in the material which zeros the change of discovering inaccuracies. Sometimes it is necessary that citizens correct the government. Our society is based on checks and balances."

Finally, one respondent expects heavy resistance. "We have to make very clear what the added value for citizens will be. Otherwise, big brother will become reality."

\subsection{Channels}

Roughly three different perspectives can be distinguished regarding service channels: internet as the primarily channel (2), channel independent service delivery (9) and a multichannel approach with specific tasks for each channel (8). Also, the appearance of new channels is mentioned by two respondents.

With the exception of two respondents, all realize that the internet is not going to be a complete substitution for traditional channels. "The best customer is the invisible customer" according to a municipal servant who believes that in the future a push to the internet will result in a complete online service delivery. A national servant agrees: "There is a huge need for the internet. In the future everything is possible online, the more complex a task the bigger the revenue for automating it. It is too expensive to maintain all channels.”

According to most respondents service delivery in the future will be channel independent. "We strive for qualitative service delivery on all channels, the customer makes the choice." However, it is believed that most processes will go digital for efficiency reasons. Respondents do prefer sending citizens to the internet: "We will be able to get the citizen to the channel we prefer. This means less personal contacts because these are expensive. But, just like banks, physical contacts will stay. It is an illusion that these will disappear." The elderly are taken into consideration as well: "We will always have to bear in mind the needs of all generations when choosing and shaping the channels. It is a wise idea to segment different groups of citizens.” 
Another popular vision is the integrated multichannel approach. "The strategy for e-service delivery in the next decennia will be applying a balanced positioning of the different channels. Channels should act in conjunction and strengthen each other. This will result in satisfied citizens and in improved effectiveness and efficiency." The respondents agree that personal contact will also play a significant role in the future. They believe that a multichannel approach results in citizens that are better prepared when visiting physical desks. Two scientists emphasize that it is important to take a more sagacious look at the nature of the different services and products. One respondent portrayed possible consequences of multichanneling: "We will be able to distinguish different groups of citizens and therefore also the weaker part that needs special attention. This will make the relationship with citizens more diverse. The government will be able to follow complaints and comments which directly results in better served citizens. All channels are going to stay, they only attract different users.”

Two respondents expect a lot from new channels. Internet will penetrate much further for simple things and integrate with other communication means. They believe that the telephone and counter will be fully integrated resulting in interactive applications where virtual servants assist citizens. "This mix of media makes reaching trouble groups of citizens possible.”

\subsection{Services}

This paragraph discusses the different services that, according to the respondents, are best suited for online availability and might serve as triggers.

Two scientists stress that it is pure guesswork to cite trigger services at this time. They strongly believe more research is needed. "The success of e-government is a non-specific feeling of quality when having contact with the government. This feeling is determined by specific services. We should perform deeper analysis of which services are used mostly, which services lack usage, which services are most emotional and about which services citizens are most frustrated. For some services citizens don't care when they don't work properly, but for others it can make them very angry”. Another respondent thinks the concept 'trigger service' is only relative because it differs in between target groups.

A municipal servant suggests taking the municipal service top 10 for every municipality: "It is possible to get a license for accessing parts of the country with horse and wagon or building a nuclear power plant. Why put effort in these services? We should make better selections instead of always making everything uniform.”

Most respondents agree on the fact that the best trigger services are those services with high volume: "People should not have to ask themselves what the returns are." This goes particularly for the category "sick, weak and obnoxious", because here citizens have a lot of contact with the government. "Most effort should be put in time intensive processes where governments have to cooperate a lot."

Another trigger service mentioned is getting a better understanding of what the government knows about citizens. This might have a direct influence on vindication too, since citizens are the best preservationists themselves.

There is one scientist who pleads for a complete computerization of society. "Then, there will be far less mistakes and a substantial increase of prosperity." 


\subsection{Number of contact moments}

Assumptions like once-only data distribution and one single online access portal suggest that the number of contact moments between citizens and government will change: they can disappear (3), decrease (10), stay constant (3) or increase (4).

One scientist describes the fundamental change in relationships between government and citizens that will take place in the coming years. "On some levels an invisible government will appear and on other levels the government will become more visible. The part were the government will be invisible alters to the electronic highway." Another scientist believes that governments will be approached differently by citizens. "Already there is much more e-mail traffic that delivers other questions and desires. Citizens expect fast answers."

Three respondents state that citizens most likely prefer no contact with governmental organizations at all. According to them an invisible government, that understands when to give what to each citizen, will come into existence. "The most efficient contact is no contact at all. This also will result in decreased risks of fraud.”

Most respondents believe that the number of contact moments will decrease for different reasons: the private sector will take over services, a better organized government will result in a reduced number of citizens that experience service problems, connected back offices will diminish the need of the government to make requests and finally, proactive service delivery will prevent citizens to come to the government with the same question over and over again. One national servant believes that the numbers will only decrease instinctively. "For some services a citizen will experience a lot of contacts and for others they won't. Some services will disappear in the back offices, but other products will become more visible.”

Finally, four respondents believe that the number of contacts will increase. A possible cause is the success of online personal portals. "Citizens will become more aware of the tasks of the government. ICT makes contact making much easier and this will directly result in an increased number of contact moments." They believe that "the government will become more and more a helpful organization."

\subsection{Digital skills}

Opinions about citizens' digital skills diverge. Four rough perspectives are: digital skills are no issue anymore (2), governments should put most effort in the digital skilled citizens (5), governments should put most effort in the laggards (4) or governments should aim at both (7).

Two respondents believe that all citizens will be able to do everything online in the near future. According to one of them this is already the case: "Research shows that when the need is there, education or race doesn't matter. Citizens will find a way to do it.” The other respondent stresses that citizens should not be underestimated. "The use of the internet, for example eBay and electronic tax declarations, is already very high, so I think the level of skill is not the problem. The problem will be connecting the next generation with their government on psychological level.”

Five respondents favor a government that aims primarily at citizens that fully participate in the digital age. One of them believes that skills will be of no concern in 
the near future because all applications will be of excellent quality. Most of them notice a shrinking group of laggards: "A toddler is already smarter then its parents. For the small group that stays behind we just maintain a traditional channel. That's it; you don't want to spend $95 \%$ of your time in $5 \%$ of the laggards.” These respondents consider it strange that exceptions are laid down as standard and do believe that governments should aim mainly at the digital skilled. Respondents in this category believe that the problem of not everybody participating will solve itself over time and that everybody eventually gets the same level of skills. Finally, one respondent brings up the discussion whether not participating in the digital age is a matter of skills: "A lot of the laggards seem to choose not to participate. A government has the obligation to give everybody access to its services, but is not a service of convenience.”

The opposite is also mentioned by a few respondents that believe the government's main task is to involve the laggards. "A homogeneous population will be much easier for eService delivery, but the reality is very different." Mentioned solutions that should prevent disadvantages for the laggards are diverse: keeping electronic service delivery as simple as possible, aiming at the average skill level of citizens, offering different search strategies, offering traditional channels, integrating electronic service delivery in education, stimulating use by rewarding citizens and finally offering proactive service delivery. These respondents agree on the fact that benefiting the digital skilled is unwanted: "Citizens vary from dinosaurs to cyber chicks. The government has the responsibility to reach them all."

Most respondents believe however, that the government should aim at both the digital skilled and the laggards. In their view, citizens that are digital skilled should be facilitated at the most and laggards should get all the help they require. "We have to create advanced services but also take care for the weak. This also requires progressiveness, but that's totally undeveloped yet.”

\subsection{Architecture}

Although not all respondents want to engage in what the future design of the electronic government looks like, there are roughly four predicted visions: one front office and one back office (1), one front office coupled to multiple back offices (4), multiple front offices coupled to one back office (2) and multiple front offices with multiple back offices (7).

One respondent wants citizens to be the owner of personal information. "Citizens will have contact with one front office. All back offices can be integrated and connected to that front office as one entity. Exchanging information has always been way too expensive. But, realizing this view suggests a total shift of paradigm.”

Three respondents plead for the development of one front office. One believes this should be the municipality. The other two suppose the development of one agency representing all detached governmental institutions. "The government will vaporize on the front office level but divided back offices will persist."

In the view of two respondents the separated front offices will stay and will be connected to one giant back office containing all governmental information. "Every organization will keep its own front office and identity. But, we should think more 
strategically resulting in a design paradigm for reinventing back offices. It is important to proclaim a catalyst for standardization of developments.”

One scientist thinks it is a typical boffin thought that one single back office will appear in the future. "Technically is it is possible to create one government, but this will never happen because every organization has its own interests and target groups. Redundancy on means and sources is not bad, but with creating one back office we will lose a lot of singularity, which will go at the expense of quality.” This respondent does believe that organizations will work more and more in accordance with government wide engagements that make data exchange possible. This is extended by one scientist by sketching the 'network oriented distributed infrastructure'. This structure is characterized by harmonization and standardization instead of centralization. "It doesn't matter that there are multiple systems. As long as data exchange between, and knowledge in the systems, is in order."

\subsection{Responsibility}

The question who should have the responsibility for realizing the different visions resulted in varying answers. Some believe that the responsibility must stay at the organizations itself so that citizens will always be able to retrieve the organization that delivers the demanded service. In contrary, four respondents request for more collaboration and shared responsibility. "Your own efficiency and methods could also work out positive for others.”

Strong leadership is also brought up: "Don't let organizations go their own way. At specific policy areas, organizations can preserve their own responsibility, but in the area of ICT we should integrate.” There is no consensus on who should take the lead. Several possibilities are mentioned. Firstly, a national project group less driven by politics. In this project group a project leader should report directly to the minister. Secondly, the State should take all responsibility for further developments of the electronic government. Thirdly, one new federal executive agency will be developed for eGovernment, represented by several governmental institutions. "When all organizations are represented, it is possible to exert more direction than currently possible.” Fourthly, members of government that can build bridges are engaged: “A strong leader in ICT will only confirm hierarchic thinking, something we have free ourselves off. We need a concern thought.” Fifthly, a private company responsible for the whole governmental administration is established. "Then you can be sure that registrations are in order." Finally, a new ministry is proposed: "Why invent service concepts independently? The problem is that everything is autonomous. That inefficiency should vanish. There should be one new ministry for operational management."

\section{Conclusions and discussion}

The results of this research indicate that Dutch leading figures in the field of eGovernment have different future visions regarding electronic public service delivery. They have different objectives, presuppositions, channel approaches and 
opinions regarding 'trigger services'. Furthermore, they don't agree on the number of contact moments between citizens and government, have different opinions regarding digital skills, plead for various architectural designs and place the responsibility for electronic service delivery in different hands.

The main conclusion is that there is no univocal future vision on electronic public service delivery in the Netherlands, both for policy advisors and scientists. A positive implication might be that exchanging ideas and approaches can have constructive effects on the quality of electronic service delivery. The diverse visions contain interesting elements ready to elaborate. This might lead to making obvious choices instead of outlining an unclear compromise policy. However, there are negative implications as well. Diverging future perspectives for example might result in the gap between supply and demand as suggested by Van Deursen et al. [4]. If this is the case, then the situation described here might not be unique for the Netherlands. When countries internally already contain varying future perspectives, presenting a common front for Europe, as stated in the Lisbon conference, seems impossible.

Most problematic however, is that some choices are extreme in that they seem to go beyond the possibilities of the political construction, at least in the Netherlands. These visions oppose both constitutional and political preconditions. It is desirable that future developments fit the political system because a revolution is unwelcome and moreover, very unlikely. Furthermore, these visions leave no room for other views in the discussion and might lead to damaged citizen's interest (e.g. excluding computer illiterates). This might also be the case when some presuppositions are carried through without a strong foundation. It is recommended that future perspectives better correspond with political point of views and show more conformity. No one benefits when policy makers follow their own path to their idea of the future.

The discussion on how to shape the future of eGovernment has been going on ever since the 1990's. Despite this, there still is a lack of concepts on how to do things. This raises the question whether the introduction of technology enables a leap forward. The results seem to suggest that automated chaos remains chaos. The principles of NPM are indeed aimed at; however, the NPM vision as body of thought alone is not sufficient. This conclusion is in line with Grönlund \& Andersson's results [10] who concluded that eGovernment research is diverse and mainly descriptive. There still is a lack of theories and eGovernment misses its own research area, as suggested by Scholl [19]. A possible explanation for the diverse visions is the fact that research lacks a uniform direction, which in turn might be explained by the fact that eGovernment researchers have different perspectives that influence the research agenda.

There are two main discussion points. First, the sample of 20 respondents is quite small. However, it is difficult to find more leading figures in the field of eGovernment in one country. Since the 20 respondents are responsible for a large part of the eGovernment policy, the results are definitively valuable. Second, the interviews took place in the Netherlands; however, it is likely that in other countries the same variety of future perspectives exist. Further research should follow, expanding the exercise to other EU countries, addressing the same kind of audience. 


\section{References}

1. Osborne, D., \& Gaebler, T. (1992). Reinventing government: How the entrepreneurial spirit is transforming the public sector. Readin: Addison-Wesley.

2. Duivenboden, H. P. M. van, \& Lips, A. M. B. (2001). Klantgericht werken in de publieke sector. Utrecht: Lemma BV.

3. Mission defined by the Innovatieplatform. Retrieved December 2006, from http://www.innovatieplatform.nl/.

4. Van Deursen, A., Van Dijk, J. \& Ebbers, W. (2006). Why E-government Usage Lags Behind: Explaining the Gap between Potential and Actual Usage of Electronic Public Services in the Netherlands. Lecture Notes in Computer Science, 4084, 269-280.

5. Van Deursen, A. \& Pieterson, W. (2006). The Internet as a service channel in the Public Sector. Paper presented at the ICA Conference, Dresden, Germany.

6. Van Dijk, J. \& Van Deursen, A. (2006). Van Aanbod naar Vraag, Tijd voor een Perspectiefwisseling. Enschede: University of Twente.

7. Aldrich, D., Bertot, J.C. \& McClure, C.R. (2002). E-Government: initiatives, developments, and issues. Government Information Quarterly, 19(4), 349-355.

8. Bekkers, V. (2002). E-Government: Meer dan E-Commerce voor Overheden. Management en Informatie, 2000(2), 11-20.

9. Sharma, S.K. (2003). Building Blocks of an e-government - A Framework. Journal of Electronic Commerce in Organizations, 1(4), 34-48.

10. Grönlund, Å. \& Andersson, A. (2006). e-Gov Research Quality Improvements Since 2003: More Rigor, but Research (Perhaps) Redefined. Lecture Notes in Computer Science, 4084, $1-12$.

11. Ministry of Labour and Citizens' Services. Retrieved December 2006, from http://www.bcbudget.gov.bc.ca/.

12. Pieterson, W. \& van Dijk, J. (2006). Governmental Service Channel Positioning: History and Strategies for the Future. In: Electronic Government. Communication Proceedings of the Fifth International EGOV Conference 2006, Krakow, Poland, 53-59.

13. Van Dijk, J., Pieterson, W., Van Deursen, A. \& Ebbers, W. eServices for Citizens: The Dutch Usage Case. (to appear in this Electronic Government issue of LNCS)

14. Deakins, E., Caves, A. \& Dillon, S.M. (2001). Issues of e-Government in the United States, Department of Management Systems Working Paper Series, No. 2001-01, 23.

15. Jaeger, P.T. \& Thompson, K.M. (2003). E-government around the world: lessons, challenges and future directions. Government Information Quarterly, 20,389-394.

16. Van Dijk, J. (2006). Digital Divide research, achievements and shortcomings. Poetics, 34, 221-235.

17. Bekkers, V. (2005). The Governance of Back-Office Integration in eGovernment: Some Dutch Experiences. Lecture Notes in Computer Science, 3591, 12-25.

18. King, N. (1994). The qualitative research interview. In C. Cassell \& G. Symon (Eds.), Qualitative methods in organizational research. A practical guide. London: Sage Publications.

19. Scholl, H.J. (2006). Is E-Government Research a Flash in the Pan or Here for the Long Shot? Lecture Notes in Computer Science, 4084, 13-24. 